DOI: 10.12731/2658-6649-2020-12-1-84-91

УДК 504.062

\title{
ДИНАМИКА МИГРАЦИИ АНТРОПОГЕННЫХ ПРИМЕСЕЙ В МАЛЫХ РЕКАХ НИЖНЕВАРТОВСКОГО РАЙОНА
}

\section{Иванова А.В.}

В исследовании рассмотрена мигращия химических вещееств в поверхностных водах и донных отложениях мальх рек Нижневартовского района. На основе данных химического анализа проб поверхностных вод и донных отложений за двенадцатилетний период, с 2007 по 2018 годы, был проведен статистический анализ всех исследованных показателей.

Ключевые слова: реки; поверхностные воды; донные отложения; химические вещуества; статистический анализ.

\section{DYNAMICS OF MIGRATION OF ANTHROPOGENIC IMPURITIES IN SMALL RIVERS OF THE NIZHNEVARTOVSK REGION}

\section{Ivanova A.V.}

The study examined the migration of chemicals in surface waters and bottom sediments of small rivers in the Nizhnevartovsk region. Based on the data of chemical analysis of surface water samples and bottom sediments for a twelve-year period, from 2007 to 2018, a statistical analysis of all the studied indicators was carried out.

Keywords: rivers; surface waters; bottom sediments; chemicals; statistical analysis.

\section{Введение}

Интенсивная добыча нефти в Западной Сибири приводит к нарушению естественного состояния экосистемы Обь-Иртышского бассейна. В результате антропогенных нагрузок на водоемы и водосборы: прокладка и реконструкция нефте- и газопроводов, зарегулирование речного стока, рост безвозвратного водопотребления и др. - происходит разрушение 
водных экосистем. При ландшафтно-геохимических исследованиях гидрографическая сеть рассматривается как основной блок, через который проходят потоки природных и техногенных веществ. Динамика химического состава поверхностных вод и донных отложений является индикатором экологической обстановки территории, что определяет значимость гидрохимических исследований речных систем.

\section{Цель исследования}

Оценка миграции химических веществ, содержащихся в поверхностных водах и донных отложениях малых рек Нижневартовского района с использованием методов статистического анализа.

\section{Материалы и методы исследования}

На основе данных многолетнего химического анализа проб донных отложений, с 2007 по 2018 годы, был проведен статистический анализ исследованных показателей. Статистическая обработка данных проводилась с использованием пакета прикладных программ Statistica и Excel.

\section{Результаты исследования и их обсуждение}

Анализ миграции химических веществ в пробах донных отложений методом скользящей средней, говорит о периодических изменениях концентраций веществ в донных отложениях (рис. 1). В донных отложениях зарегистрированы резкие пики и спады концентраций химических веществ: максимальные пики отмечены в 2008 и 2012 году, минимальные концентрации веществ в 2010, 2013 и 2014 годах. В целом прогноз изменения химического состава донных отложений методом скользящей средней показал изменение количества веществ за двенадцатилетний период в диапазоне от 23 до 250 мг/кг, в 2008 году этот показатель составил 250 мг/кг, в $2018-148$ мг/кг.

Прогноз миграции химических веществ в донных отложениях методом скользящей средней за исследуемый период показывает, что с 2007 по 2011 гг. наблюдаются резкие изменения концентраций веществ, а далее кривая имеет сглаженный вид по сравнению с фактическими показателями. Фактическое суммарное количество химических веществ в донных отложениях в несколько раз превышают аналогичные показатели веществ в поверхностной воде, что связано с переходом химических веществ из воды в донные отложения в результате физических процессов самоочищения воды. В накоплении веществ в донных отложениях прослеживается 
периодичность, обусловленная сезонными и многолетними колебаниями режима водоемов.

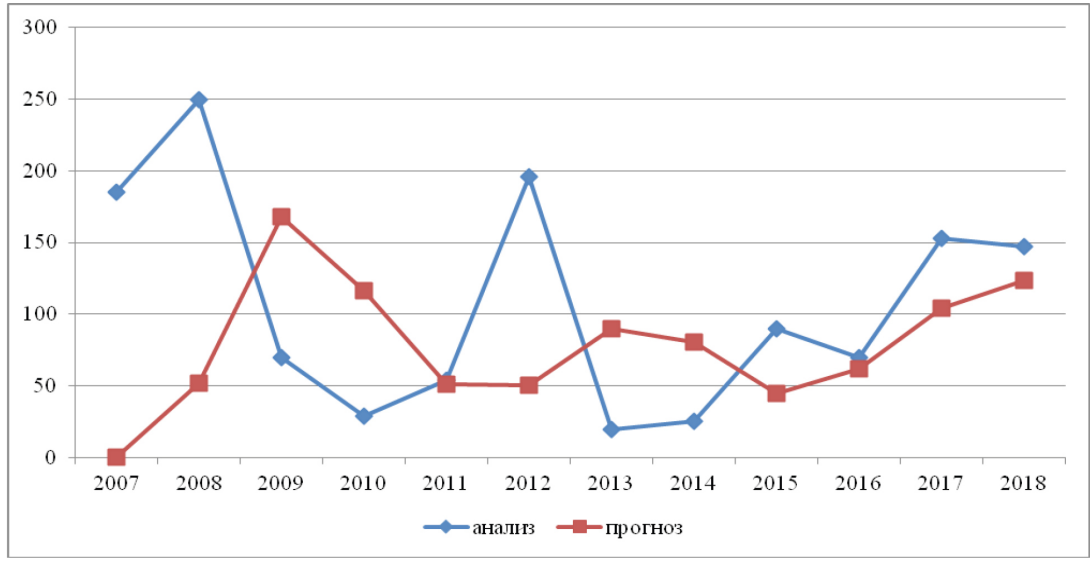

Рис. 1. Анализ и прогноз миграции химических веществ в пробах донных отложений исследованных рек методом скользящей средней

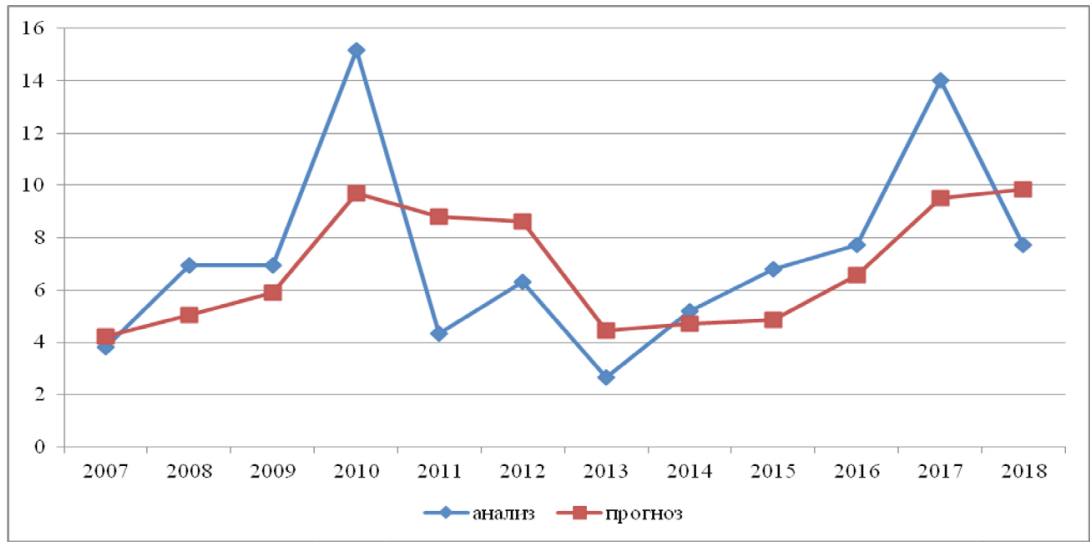

Рис. 2. Анализ и прогноз миграции химических веществ в пробах поверхностных вод исследованных рек методом скользящей средней

Анализ миграции химических веществ в пробах поверхностных вод методом скользящей средней за период с 2007 г. по 2018 год, говорит о значительном колебании суммарного количества химических веществ (рис. 2). С 2007 по 2010 год суммарное количество химических веществ 
увеличивалось, с 2010 по 2013 уменьшалось, затем опять увеличивалось. Пики концентрации веществ отмечаются в 2010, 2017 годах, с 2010 года по 2013 год отмечается снижение концентраций веществ в пробах воды рек Нижневартовского района, в 2017 году регистрируется значительное повышение, к 2018 годы идет спад концентрации химических веществ.

«Кривая» прогноза миграции химических веществ в пробах воды методом скользящей средней за двенадцатилетний период (2007-2018 год), имеет более сглаженный вид, в сравнении с фактическими показателями. Принято считать, что антропогенное воздействие усиливается с каждым годом и количество загрязнителей растет, как видно из прогноза, методом скользящей средней за 12-летний период исследования, концентрации химических веществ в воде рек Нижневартовского района изменяется волнообразно. Что объясняется процессами самоочищения в экосистемах.

Степень корреляционной зависимости количества химических веществ в поверхностных водах и донных отложениях малых рек северной части Нижневартовского района характеризуется как положительная средняя, и составила $\mathrm{r}=0,62955$.

\section{Заключение}

Результаты проведенного нами исследования показывают, что речные системы Нижневартовского района, протекающие по территории лицензионных участков, активно подвергаются промышленному воздействию со стороны нефтегазодобывающей отрасли. Промышленные площадки и автодороги на лицензионных участках оказывают техногенное воздействие на поверхностные воды и донные отложения малых рек Нижневартовского района. Анализ и прогноз миграции химических веществ в пробах воды и донных отложений исследованных рек методом скользящей средней за двенадцатилетний период (2007-2018 год), говорит о значительном колебании суммарного количества химических веществ. В пробах воды и донных отложениях зарегистрированы резкие пики и спады концентраций химических веществ, в целом динамика имеет волнообразный характер.

\section{Список литературы}

1. Александрова В.В., Левкова А.Н., Логинов Д.Н., Иванов В.Б. Анализ и прогноз миграции антропогенных примесей в пробах донных отложений поверхностных вод Нижневартовского района // В мире научных открытий. 2017. № 9 (4-2). 180-186. 
2. Александрова В.В. Применение метода биотестирования в анализе токсичности природных и сточных вод (на примере Нижневартовского района Тюменской области): Монография. Нижневартовск: Изд-во НГГУ, 2009. $92 \mathrm{c}$.

3. Александрова В.В. Анализ корреляционной зависимости выживаемости и плодовитости тест-объекта Ceriodaphnia affinis с химическим составом воды // Вестник Нижневартовского государственного университета. 2013. № 3. С. 60-63.

4. Александрова В.В. Определение качества природных вод методом биотестирования в полевых условиях // Известия Самарского научного центра Российской академии наук. 2013. Т. 15. № 3 (3). С. 897-899.

5. Александрова В.В., Левкова А.Н., Иванова А.В. Анализ и прогноз миграции химических веществ в поверхностных водах и донных отложениях малых рек // Siberian Journal of Life Sciences and Agriculture. 2019. T. 11. №2-2. C. 12-20.

6. Александрова В.В., Иванов В.Б., Иванов Н.А., Марач В.С. Оценка качества воды озер Нижневартовского района по критерию выживаемости Daphnia magna // В мире научных открытий». 2017. Т. 9. № 1-2. С. 36-41.

7. Александрова В.В. Биотестирование как современный метод оценки токсичности природных и сточных вод. Нижневартовск, 2013.

8. Александрова В.В., Иванов Н.А., Марач В.С., Иванов В.Б. Оценка токсичности вод озер Нижневартовского района // В мире научных открытий. 2017. Т. 9. № 2-2. С. 53-57.

9. Александрова В.В., Логинов Д.Н., Войтова В.А. Корреляционный анализ миграции антропогенных примесей в донных отложениях методом химического анализа // В мире научных открытий. 2017. Т. 9. № 4-2. С. 186-191.

10. Волков И.М., Ряхин М.С., Белоусов С.Н., Александрова В.В., Иванов В.Б. Обеспечение экологической безопасности проектных решений на территории лицензионных участков недропользователей с применением наилучших доступных технологий // Нефтяное хозяйство. 2018. № 2. С. 109-112.

11. Иванов В.Б., Усманов И.Ю., Александрова В.В., Иванов Н.А., Болотин К.И., Иванова Л.Г., Копылов Е.О. Количественные и качественные критерии преобразования и самовосстановления природных комплексов в результате загрязнения нефтепродуктами // В мире научных открытий. 2017. T. 9 (1-2). C. 56-65.

12. Иванов В.Б., Усманов И.Ю., Александрова В.В., Иванов Н.А., Калиновская Е.А. Оценка воздействия нефтешламовых амбаров на верховые болотные почвы // В мире научных открытий. 2017. Т. 9 (1-2). С. 66-71. 
13. Иванов В.Б., Калиновская Е.А., Иванов Н.А., Александрова В.В., Усманов И.Ю. Геохимическая оценка воздействия шламовых амбаров на верховые болотные почвы // В мире научных открытий. 2017. Т. 9. № 2-2. С. 23-28.

14. Иванов В.Б., Федоренко Л.З., Иванова Л.Г. Оценка сезонной динамики качества поверхностных вод по критерию плодовитости Ceriodaphnia affinis // В мире научных открытий. 2018. Т. 10. № 1-2. С. 38-45.

15. Иванов В.Б., Долгих А.Ю. Оценка экологического состояния водного объекта // Siberian Journal of Life Sciences and Agriculture. 2019. T. 11. № 3-2. C. 21-28.

16. Левкова А.Н., Иванов В.Б. Эколого-химический анализ состояния донных отложений малых рек Нижневартовского района в зоне воздействия нефтедобывающей промышленности // XIX Всероссийская студенческая научно-практическая конференция Нижневартовского государственного университета. Нижневартовск: Изд-во НВГУ, 2017. С. 355-360.

17. Толкачева В.В. Анализ токсичности природных вод методом биотестирования (на примере Нижневартовского района) / Диссертация на соискание ученой степени кандидата биологических наук. Омск: ОмГПУ, 2004.

18. Толкачева В.В. Анализ токсичности природных вод методом биотестирования (на примере Нижневартовского района) : Автореферат диссертации на соискание ученой степени кандидата биологических наук. Омск: ОмГПУ, 2004. $22 \mathrm{c}$.

19. Усманов И.Ю., Иванов В.Б., Иванов Н.А. Самовосстановление экосистем Среднего Приобья при антропогенных воздействиях нефтедобывающего комплекса // Экологические проблемы бассейнов крупных рек - 6: Материалы международной конференции. Тольятти: Анна, 2018. С. 303-305.

20. Ivanov V.B., Alexandrova V.V., Usmanov I.Yu., Scherbakov A.V., Yumagulova E.R, Ivanov N.A., Chibrikov O.V. Comparative Evaluation of Migrating Anthropogenic Impurities in Ecosystems of the Middle Ob Region through Bioindication and Chemical Analysis // Vegetos: An International Journal of Plant Research. 2016. Vol. 29. № 2, pp. 47-50.

\section{References}

1. Aleksandrova V.V., Levkova A.N., Loginov D.N., Ivanov V.B. V mire nauchnyh otkrytij. 2017. №9 (4-2), pp. 180-186.

2. Aleksandrova V.V. Primenenie metoda biotestirovaniya $v$ analize toksichnosti prirodnyh $i$ stochny vod (na primere Nizhnevartovskogo rajona Tyumenskoj oblasti) [Application of the bioassay method in the analysis of toxicity of natural and waste waters (for example, Nizhnevartovsk district of the Tyumen region)]. Nizhnevartovsk: Izd-vo NGGU, 2009. 92 p. 
3. Aleksandrova V.V. Vestnik Nizhnevartovskogo gosudarstvennogo universiteta. 2013. № 3, pp. 60-63.

4. Aleksandrova V.V. Izvestiya Samarskogo nauchnogo centra Rossijskoj akademii nauk. 2013. V. 15. № 3 (3), pp. 897-899.

5. Aleksandrova V.V., Levkova A.N., Ivanova A.V. Siberian Journal of Life Sciences and Agriculture. 2019. V. 11. №2-2, pp. 12-20.

6. Aleksandrova V.V., Ivanov V.B., Ivanov N.A., Marach V.S. V mire nauchnyh otkrytij. 2017. V. 9. № 1-2, pp. 36-41.

7. Aleksandrova V.V. Biotestirovanie kak sovremennyj metod ocenki toksichnosti prirodnyh i stochnyh vod [Biotesting as a modern method for assessing the toxicity of natural and waste waters]. Nizhnevartovsk, 2013.

8. Aleksandrova V.V., Ivanov N.A., Marach V.S., Ivanov V.B. V mire nauchnyh otkrytij. 2017. V. 9. № 2-2, pp. 53-57.

9. Aleksandrova V.V., Loginov D.N., Vojtova V.A. Vmire nauchnyh otkrytij. 2017. V. 9. № 4-2, pp. 186-191.

10. Volkov I.M., Ryahin M.S., Belousov S.N., Aleksandrova V.V., Ivanov V.B. Neftyanoe hozyajstvo. 2018. № 2, pp. 109-112.

11. Ivanov V.B., Usmanov I.Yu., Aleksandrova V.V., Ivanov N.A., Bolotin K.I., Ivanova L.G., Kopylov E.O. V mire nauchnyh otkrytij. 2017. V.9 (1-2), pp. 56-65.

12. Ivanov V.B., Usmanov I.Yu., Aleksandrova V.V., Ivanov N.A., Kalinovskaya E.A. V mire nauchnyh otkrytij. 2017. V. 9 (1-2), pp. 66-71.

13. Ivanov V.B., Kalinovskaya E.A., Ivanov N.A., Aleksandrova V.V., Usmanov I.Yu. V mire nauchnyh otkrytij. 2017. V. 9. № 2-2, pp. 23-28.

14. Ivanov V.B., Fedorenko L.Z., Ivanova L.G. V mire nauchnyh otkrytij. 2018. V. 10. № 1-2, pp. 38-45.

15. Ivanov V.B., Dolgih A.Yu. Siberian Journal of Life Sciences and Agriculture. 2019. V. 11. № 3-2, pp. 21-28.

16. Levkova A.N., Ivanov V.B. XIX Vserossijskaya studencheskaya nauchno-prakticheskaya konferenciya Nizhnevartovskogo gosudarstvennogo universiteta [XIX All-Russian Student Scientific and Practical Conference of the Nizhnevartovsk State University]. Nizhnevartovsk: Izd-vo NVGU, 2017. P. 355-360.

17. Tolkacheva V.V. Analiz toksichnosti prirodnykh vod metodom biotestirovaniya (na primere Nizhnevartovskogo rayona) [The analysis of the toxicity of natural waters by the bioassay method (on the example of the Nizhnevartovsk region)]. The dissertation for the degree of candidate of biological sciences. Omsk: OmGPU, 2004.

18. Tolkacheva V.V. Analiz toksichnosti prirodnyh vod metodom biotestirovaniya [The analysis of the toxicity of natural waters by the bioassay method (on the example of the Nizhnevartovsk region)]. Omsk: OmGPU, 2004. 22 p. 
19. Usmanov I.Yu., Ivanov V.B., Ivanov N.A. Ekologicheskie problemy bassejnov krupnyh rek - 6: Materialy mezhdunarodnoj konferencii [Ecological problems of large river basins - 6: Materials of an international conferenc]. Tol'yatti: Anna, 2018, pp. 303-305.

20. Ivanov V.B., Alexandrova V.V., Usmanov I.Yu., Scherbakov A.V., Yumagulova E.R, Ivanov N.A., Chibrikov O.V. Comparative Evaluation of Migrating Anthropogenic Impurities in Ecosystems of the Middle Ob Region through Bioindication and Chemical Analysis. Vegetos: An International Journal of Plant Research. 2016. Vol. 29. № 2, pp. 47-50.

\section{ДАННЫЕ ОБ АВТОРЕ}

Иванова Ангелина Вячеславовна, студент

ФГБОУ ВО «Нижневартовский государственный университет» ул. Ленина, 56, г. Нижневартовск, 628605, Российская Федераџия karatazh@mail.ru

\section{DATA ABOUT THE AUTHOR}

\section{Ivanova Angelina Vyacheslavovna, student}

Nizhnevartovsk State University

56, Lenin St., Nizhnevartovsk, 628605, Russian Federation

karatazh@mail.ru 